no longor applies; size criteria are given liberally for adults, eggs and other characteristics and for the majority of species, even when these are numerous in a genus. There arc many references concerning experimental infections and information concerning larval forms and intermediate hosts in excess of what could bo expected in a systematic essay, and a good general account of structure by way of introduction. In short, the blemishes noticed in preceding volumes have been avoided in this volume, although a few typographical errors are evident. This is not surprising in viow of the plethora of phantasmagorial names such as Acanthocephalorhynchoides ussuriense, and an occasional lapse, such as in 'Arythmorhynchus' (p. 395) and 'Gigantorhynchus' (p. 404), is pardonable. The names of authors provide their own typographical problem, but it is odd to find, closely following a tribute to dedicated bibliographers working in the Catalogue Room at the Beltsville Parasitological Laboratory, that Yamaguti is indecisivo and rocalcitrant about the spelling of the name Petroschenko, which appears thus in the Index-Catalogue. A.t the same time, we have to thank Yamaguti for a sustained attompt to present scientific names accurately and a determined effort to provide a reliable taxonomic scheme, which at best can only be provisional. It is to be hoped that readers will realizo how often and with what magistorial serenity Yamaguti had adjudicated in the face of difficulties created by writers who produced imperfect and defective work. It is a lamentablo fact that much bad workmanship is evident in the original literature on the systematics of helminths and perhaps the greatest value of Yamaguti's great efforts will lio in the direction of better descriptions of species and genera in the future than have often been forthcoming, with more emphasis on the range of their variability. A taxonomic scheme will bo as reliable as the work of the taxonomist and no more reliable, and with this admonition to the would-be systematist in the fiold of parasitology wo can leave Yamaguti's Systema Helminthum in what we hope will be good hands.

BEN DAwes

\section{CALCULATIONS IN COMPLEXOMETRIC ANALYSIS}

Complexation in Analytical Chemistry

A Guide for the Critical Selection of Analytical Methods Based on Complexation Reactions. By Anders Ringbom. (Chemical Analysis: a series of Monographs on Analytical Chemistry and Its Applications, Vol. 16.) Pp. $x+395$. (New York and London: Interscionce Publishers, a Division of John Wiley and Sons, 1963.) $113 s$.

COMPLEXATION reactions are now widely used in $C_{\text {analytical chemistry and it is not unusual for the }}$ analyst to have to ehoose between several complexometric methods of analysis and for him to have difficulty in selecting the method which will give the most accurate result. Alternatively a method may need modification to suit the particular circumstances of the analysis. Such problems are frequently resolved as the result of $a$ series of inconclusive experiments, or by the personal prejudice of the analyst, as insufficient time is available for a more complete investigation. A rapid, less empirical, approach has been long overdue.

In Complexation in Analytical Chemistry Ringbom shows that an increased application of theoretical principles to chemical analysis-in particular to complexation reactions-can greatly assist the analyst in making rapid and accurate decisions concerning the choice of analytical procedures. A simple mathematical treatment of equilibria is presented and this enables the analyst to establish the optimum experimental conditions for complexation reactions. Existing methods of analysis can be compared for determining their relative accuracies. Errors caused by various side reactions can be estimated and ways of reducing or eliminating the interferences can be quantitatively studied. There are also interesting possibilities of developing new methods for solving special analytical problems.

The mathematical treatment is lucidly explained and illustrated by more than a hundred examples. Analysts, once they understand the basic principles on which the calculations are based, should have no difficulty in making such calculations, as may be necessary, to assist in solving particular problems.

Complexation reactions are treated in their broadest sense, chapters being devoted to titrations, masking, acid-base reactions, ion-exchange, metal extraction, olectrochemical reactions and photometric techniques. Actual methods for particular analyses are not given as the object of the book is to enable the analyst to devise these for himself and no attempt is made at reviewing the literature on complexation reactions in analytical chemistry. An extonsive appendix, more than one-fifth of the book, contains details of equilibrium constants and other useful values abstracted from the literature. Notwithstanding the extent of the appendix, the main limitation to this simple mathematical approach to complexation reactions is the lack of the relevant equilibrium data for many reactions of interest.

The book is well produced and the text is clearly arranged; but it seems unfortunate that a work which is intended to assist the analyst in solving everyday analytical problems could not have been more attractively priced.

J. R. COOKE

\section{AN ENCYCLOPADIA OF INORGANIC ANALYTICAL CHEMISTRY}

Methods of Quantitative Inorganic Analysis

An Encyclopedia of Gravimetric, Titrimetric and Colorimetric Methods. By Kazunobu Kodama. Pp. xiv + 507. (New York and London: Interscience Publishers, a Division of John Wiley and Sons, 1963.) $160 s$.

A NUMBER of works on inorganic analytical chemistry, often running to several volumes, have appeared in recent years to meet the demand of analysts for organized compilations from the original literature. This present treatise, Methods of Quantitative Inorganic Analysis, represents an interesting and generally successful attempt at compressing a wide range of detailed material within the compass of a single volume. Dr. Kodama has achieved this difficult task by efficient arrangement of material and by adoption of an abbreviated style reminiscent of that of Chemical Abstracts. Theoretical discussions and diagrams of apparatus have been omitted and there has been some sacrifice of typographical clarity. However, there are some fifty-nine tables where a great wealth of varied and analytical data is clearly and concisely presented.

Originally, the author intended this treatise to cover a wider field than that now presented but limitations of space have precluded any treatment of purely physical techniques such as spectrographic, X-ray fluorescent, radiometric methods, etc. The scope of Methods of Quantitative Inorganic Analysis is exactly described by its sub-title: An Encyclopedia of Gravimetric, Titrimetric and Colorimetric Methods. However, where flame photometry is an important method of analysis references are given to the pertinent literature, but polarographic methods which are valuable in metal alloy analysis are given no mention.

The book is divided into three parts, each representing a different and complementary aspect of inorganic analysis. For a particular problem it will often be necessary for the analyst to consult and combine material from each part. 